\title{
Development Mode of Cold-chain Logistics of Guangxi Agricultural Products and Innovation Strategies
}

\author{
Weiyu Zhong \\ Hunan International Business Vocational College, Changsha, 410021, China
}

\begin{abstract}
Keywords: Guangxi agricultural products; Cold-chain logistics; Logistics mode; Innovation strategies
\end{abstract}

\begin{abstract}
Guangxi has rich resource in agricultural products; meanwhile, it is also a bridgehead for China to import agricultural products from ASEAN countries. Therefore, the development of cold-chain logistics of Guangxi agricultural products is especially important, and the cold-chain logistics is an important means of serving for "three rural" in Guangxi. This paper carries out further discussion based on the development of cold-chain logistics of Guangxi agricultural products, analyzes the existing problems, and then proposes the innovation strategies for the development mode of cold-chain logistics of Guangxi agricultural products according to actual condition, which greatly improves the market-oriented degree of cold-chain logistics of Guangxi agricultural products and improves the service quality.
\end{abstract}

\section{Introduction}

As for agricultural products, the deterioration can easily happen due to the influence of change in external conditions such as temperature and humidity. Therefore, in order to guarantee the fresh degree of agricultural products, we need to adopt special handling method for agricultural products in the transportation process; in other words, we adopt low-temperature storage for the agricultural products, that is, cold-chain logistics mode. Then, as a large province with agricultural production in China, Guangxi province has excellent geographical environment and rich resource in agricultural products which are sold throughout China. Meanwhile, Guangxi also serves as a bridgehead for transaction between China and ASEAN countries, and it especially undertakes the task of importing agricultural products from ASEAN countries. Therefore, Guangxi shall have an in-place development of cold-chain logistics of agricultural products so that the cold-chain logistics can truly become an important means of serving for "three rural” in Guangxi.

\section{Current development of cold-chain logistics of Guangxi agricultural products and problems}

Due to the fact that the development of cold-chain logistics of Guangxi agricultural products is still under preliminary stage, there still exist some problems, and there is still a long way to meet the requirement of modern agriculture and service industry. The specific representations are shown as below:

\section{Low coverage rate of cold-chain logistics}

Although Guangxi is a large province in production of agricultural products, due to backward economic development condition and lack of necessary hardware and software investment, the coverage rate of cold-chain logistics of agricultural products is low. In fact, as for agricultural products for which the deterioration can easily happen, it is required to keep the stipulated low-temperature environment in the links of production, processing, storage, transportation, sales, and consumption so as to reduce the loss rate of agricultural products to minimum degree. However, the current trend of economic development in Guangxi can't adapt to high-requirement development mode of cold-chain logistics of agricultural products, and the cold-chain logistics of partial agricultural products only has a coverage rate of $8 \%$; as for most of agricultural products, the logistic management is still carried out under room temperature, which enhances the loss rate of agricultural 
products; it is estimated that the loss is more than ten billion yuan and such loss is ranked in front row in China.

\section{Backward facilities of cold-chain logistics}

The demand of Guangxi agricultural products increases day by day, and the corresponding demand of cold-chain logistics of agricultural products also show a trend of continuously rising. However, due to backward economy, the infrastructure ability of cold-chain logistics of Guangxi agricultural products is seriously insufficient, with low cold storage and transportation ability and aging equipments, which obviously influences the further development of cold-chain logistics of agricultural products. Even in developed regions in China, the per capita refrigeration is dozens of times lower than that in developed countries such as the United States. Then, as a region with backward economic development, Guangxi has limited refrigeration ability. So far, only several enterprises in Guangxi have refrigeration houses with a capacity of above 10,000t-level, and most of enterprises have the medium and small-size refrigeration houses with limited capacity; some refrigeration houses are even established in 1990s. Therefore, those refrigeration houses have low technical content and can't adapt to the current high demand of cold-chain logistics of agricultural products.

\section{Low market-oriented degree of cold-chain logistics}

The foreign developed countries have had standard and systematic cold-chain logistics management system for agricultural products; the cold-chain logistics is basically managed by logistics companies with strong fund and large scale, thus it has high degree of organization. However, the subjects in cold-chain logistics of Guangxi agricultural products are basically some weak peasants and private operators, which causes small scale, weak market competitiveness and failure in obtaining the due scale benefit. Furthermore, the development of cold-chain logistics of Guangxi agricultural products is imbalanced, and there is still no accurate statistical data of quantity of refrigeration houses. The insufficient processing of agricultural products, low output value, no effective coordination in cold-chain logistics system, and even "break of chain" cause low market-oriented degree of cold-chain logistics of Guangxi agricultural products; most of cold-chain logistics suppliers have low service quality and no accurate and timely service, which greatly influences the normal development of cold-chain logistics market.

\section{Insufficient professional talents in cold-chain logistics}

As the professional talents in cold-chain logistics of agricultural products, they must have general knowledge and skills of logistics management, master corresponding refrigeration technique and low-temperature management knowledge, and get a deep knowledge of agricultural products. However, as a large province with slow economic development, Guangxi is also backward in talent cultivation; besides, the cold-chain logistics belongs to an emerging field in logistics field, thus it is not an easy thing for Guangxi to cultivate professional cold-chain logistics talents. Therefore, the insufficient talents in cold-chain logistics of Guangxi agricultural products has become a large "bottleneck" which restricts the healthy and rapid development of cold-chain logistics, for no special cold-chain logistic courses are set in some colleges in Guangxi. Certainly, although the cold-chain logistics management specialty has been set in some other colleges, the number of talents is too small to meet the demand of cold-chain logistics market.

\section{Innovation strategies for development mode of cold-chain logistics of Guangxi agricultural products}

As a large agriculture province, the development of cold-chain logistics in Guangxi is of great importance and necessity, and the cold-chain logistics will be one of effective measures used to solve the "three rural" issues and it is of great additional value. However, in terms of current situation, the development of cold-chain logistics of Guangxi agricultural products is still under preliminary stage and the cold-chain logistics lacks of scientific and modern perfect logistics system, which greatly restricts its development. Therefore, Guangxi shall innovate development mode of cold-chain logistics of agricultural products and practically exert the positive promotion function of cold-chain 
logistics on agricultural products as soon as possible. The specific innovation strategies are shown as below:

\section{The government shall formulate and perfect relevant cold-chain logistics mechanism}

The cold-chain logistics of Guangxi agricultural products has a lagging development, which is greatly related with the fact that the local government doesn't provide a perfect management mechanism. Therefore, as a macro-economy manager, the government shall make full use of the public power on its hand to formulate and continuously perfect relevant cold-chain logistics mechanism for agricultural products. On one hand, the government shall adopt incentive mechanism to fully motivate the enthusiasm and initiative of cold-chain logistics subjects, and then stimulate their behavioral motive. On the other hand, the government shall also perfect corresponding supervision mechanism and strictly manage the cold-chain logistics subjects so that their behavioral objective can meet the overall development objective of whole cold-chain logistics industry and the society.

In terms of incentive mechanism, the government department shall issue more support policies to stimulate people's enthusiasm in investment in cold-chain logistics for agricultural products, and attract more fund to enter into cold-chain logistics industry to let them support the construction and development of infrastructure of cold-chain logistics of Guangxi agricultural products. Besides, the government can also make use of various kinds of preferential policies to attract more cold-chain logistics enterprises to enter into market competition, encourage and help them to develop more cold-chain logistics technology, further integrate cold-chain logistics system, reform some state-owned agricultural products enterprises, and expand the application of modern new network technology so that the cold-chain logistics mode of Guangxi agricultural products can have higher efficiency and profits. Except for incentive mechanism, the government department shall also enhance the supervision mechanism on cold-chain logistics of agricultural products; this is because the current cold-chain logistics of agricultural products lacks of necessary industrial standard, which causes low efficiency of cold-chain logistics and influences healthy development of whole cold-chain logistics industry. Therefore, the government department shall formulate a uniform cold-chain logistics standard and scientific supervision mechanism to carry out special remediation on cold-chain logistics of agricultural products and establish corresponding punishment system and credit system. Certainly, except for perfecting those mechanisms, the government shall also break current industrial segmentation in cold-chain logistics of agricultural products from macroscopical perspective so as to provide a stable cold-chain logistics market environment for smooth implementation and further perfection of above mechanisms.

\section{The enterprises shall continuously enhance their service awareness and improve the operation efficiency of service}

As the subject of cold-chain logistics of agricultural products, the logistics enterprises face great challenges, for Guangxi, as a large province in production, transportation, and sales of agricultural products, undertakes heavy import and export task. However, due to influence and limitation of multiple factors, Guangxi still lacks of mature cold-chain logistics system, and there are only few large-scale enterprises of cold-chain logistics; most of cold-chain logistics enterprises still belong to medium and small-sized enterprises, and they can't fully meet the development demand of cold-chain logistics of Guangxi agricultural products. Therefore, in order to change this situation, the cold-chain logistics enterprises in Guangxi shall face the reality, seize various chances and meet various changes, try their best to improve their service awareness and service function so as to continuously improve their operation efficiency.

Then, the few large-scale cold-chain logistics enterprises in Guangxi can be regarded as the core enterprises in Guangxi cold-chain logistics industry, and they shall continuously integrate and plan the cold-chain logistics of agricultural products in Guangxi. Specifically speaking, they shall carry out an overall planning on cold-chain hardware facilities in Guangxi according to actual condition and features of cold-chain logistics of agricultural products in Guangxi, and also plan the layout of 
software facilities such as consumer service system so as to realize seamless connection of whole cold-chain logistics system of agricultural products. As for some non-professional cold-chain logistics enterprises, they can encourage and develop third-party logistics to improve their operation efficiency, and they can regard professional third-party cold-chain logistics enterprises as their effective breach; therefore, the agricultural products enterprises shall establish a set of complete cold-storage chain, and select third-party logistics enterprises with complete facilities and high technical content to undertake all cold-chain logistics businesses of the enterprises. Certainly, the agricultural products enterprises can also formulate distribution strategy to let the agricultural product cold-chain logistics industry improve service level, reduce distribution cost, and realize scale merit.

It is required to enhance the technical content and improve equipment quality of cold-chain logistics industry

One of development bottlenecks in the cold-chain logistics industry of Guangxi agricultural products is lagging in technology and old equipments. Therefore, Guangxi shall keep up with the change of market demand, integrate the whole cold-chain logistics system of agricultural products, and especially enhance the construction and perfection of cold-chain logistics information management system so as to practically realize the reasonable integration of cold-chain system through sharing and effective delivery of cold-chain logistics information, such as inventory control system and transportation management system. If the agricultural products cold-chain logistics enterprises can perfect those information management systems, they can improve the technical content of cold-chain logistics industry and effectively reduce the logistics expenditure of enterprises, as well as timely and quickly obtain relevant logistics information through those logistics management software, which can greatly improve the working efficiency and level of cold-chain logistics enterprises. Therefore, Guangxi shall especially enhance the information content of cold-chain logistics industry of agricultural products and improve the updating speed of equipments, such as application of GIS, GPS technology and POS technology.

The improvement of technical content and equipments updating of cold-chain logistics of agricultural products can't be separated from relevant professional talents' participation. In view of the fact that Guangxi seriously lacks of professional cold-chain logistics talents at present, Guangxi shall cultivate professional talents, and attract and gather large quantity of excellent logistics talents as soon as possible. Therefore, it is required to provide professional cold-chain logistics talents from some institutions of higher learning and research institutions, and also cultivate a batch of professional cold-chain logistics talents through holding special training class by enterprises and relevant organizations so as to let cold-chain logistics enterprise step on a healthy development road of "industry-university-research cooperation”.

\section{Conclusion}

In conclusion, Guangxi has rich agricultural products and undertakes the task of transaction of agricultural products with ASEAN countries, thus the development of its cold-chain logistics is under great pressure. However, due to limited economic level, the development of cold-chain logistics of agricultural products is also limited. Therefore, Guangxi shall enhance the construction of infrastructure of cold-chain logistics, standardize professional market of agricultural products cold-chain logistics, highlight its advantages, make upstream and downstream cold-chain logistics supply chain market connected together, exploit the market, expand the circulation channels of cold-chain logistics, and depend on advanced science and technology to promote information-based construction of cold-chain logistics; in this way, it is able to truly innovate the development mode of its cold-chain logistics industry, let the cold-chain logistics truly serve for Guangxi “three rural” issue, and represent its additional value under the condition of policy support from government, modern technology and perfect equipments, expanded professional talents, and integration of agricultural products cold-chain logistics industry in Guangxi. 


\section{References}

[1] Chen Lihua, Gong Tianxiao: Problems Existing in Cold-chain Logistics of Agricultural Products and Development Strategies, Logistics and Material Handling, 2011 (2): 68-68.

[2] Hong Tao, Qian Chunyan: Quicken the Development of Cold-chain Logistics of Agricultural Products in China, Heilongjiang Food, 2011 (4): 14-17.

[3] Liu Jiajia, Hong Weifeng, Zhang Haiyan: Discussion on Optimization Strategies for Cold-chain Logistics of Agricultural Products in China, Logistics Management, 2011 (1): 49-51.

[4] Qin Yitan, Tang Liansheng: Development Status of Cold-chain Logistics of Fresh Fruits and Vegetables in Guangxi and Suggestions, China Economic \& Trade Herald, 2012 (1): 24-26.

[5] Wang Chuanlei, Gao Wenyi, Wang Ruzheng: Cold-chain Logistics Market Analysis - take cold-chain market of agricultural products in Hefei City as an example, Logistics Engineering And Management, 2011 (3): 70-73. 